\title{
"CONTINUIDAD DE LOS PARQUES": UNA POÉTICA DE LECTURA
}

\author{
"Continuidad de los parques": a poetry reading
}

\section{Silvia Elena Solano Rivera*}

\begin{abstract}
RESUMEN
En este artículo propongo una nueva lectura de "Continuidad de los parques" (1956), de Julio Cortázar, uno de los cuentos más estudiados por la crítica hispanoamericana. En las múltiples lecturas del cuento ha primado un enfoque inmanentista que parte de la perspectiva de lo fantástico desde Todorov, enfoque nada favorable para la poética de la lectura sobre la cual está construido el texto. Mi lectura de "Continuidad de los parques" consiste en ver el cuento como un poética de la lectura, como un deber ser del proceso de leer, ya que el personaje principal es el lector de una novela que terminará por matarlo debido a su manera superficial y ligera de leer. Lo cual se nos muestra a los lectores de modo ejemplarizante, marca un cómo no se debe leer y por lo tanto sienta las bases de un modelo y un antimodelo de lector.

Palabras clave: cuento latinoamericano, Julio Cortázar, literatura fantástica, recepción.
\end{abstract}

\begin{abstract}
In this article I propose a new reading of "Continuidad de los parques" (1956), by Julio Cortázar, one of the most studied by the hispanic american critic. Thoughout the multiple readings of this short story, an immanent reading has prevailed. It has been fundamented in the theory of the fantastic by Tzvetan Todorov, an unfavorable point of view for this text's structure. My reading of "Continiudad de los parques" considers this short story as a poetics of reading, as a should-be of the reading process, taken that the principal character is the reader of a novel that will end up killing him due to his superficial way of reading. This is shown to us readers as an example of how a reader should not read and, in consequence, sets the bases of a model and anti-model of reader.
\end{abstract}

Key Words: Latin-American short stories Julio Cortázar, fantastic literature, reception.

Escuela de Filología, Lingüística y Literatura. Universidad de Costa Rica. Costa Rica Correo electrónico: silisori@gmail.com Recepción: 6/05/2014. Aceptación: 6/11/2014. 
Un lector pasivo es como un marido cornudo atacado por la espalda sorpresivamente.

Alberto Paredes

El asesinato del lector en la obra, es en última instancia, un asesinato epistemológico. Lo que muere en el texto es todo un concepto de lectura como asimilación de productos 'premasticados'.

Santiago Juan Navarro

\section{La continuidad de la inmanencia: lecturas de "Continuidad de los parques"}

Mucha tinta se ha vertido sobre el famoso cuento "Continuidad de los parques", de Julio Cortázar, texto que aparece publicado por primera vez en el cuentario Final del juego de 1956. Sin embargo, considero conveniente un examen riguroso de la crítica que ha suscitado, ya que parto de la tesis de que ha primado en dicha crítica un enfoque inmanentista, nada favorable para la poética de la lectura sobre la cual está construido.

Al revisar los estudios sobre "Continuidad de los parques" es evidente que la gran mayoría de la crítica se queda en análisis inmanentes, cuyos enfoques apuntan de manera unánime a señalar el texto como fantástico y los procedimientos y recursos que emplea para serlo. Dentro de esta vertiente se encuentra el estudio de Lagmanovich (1972), quien se ocupa de caracterizar el cuento con los rasgos de literaturización y enmarcación. La literaturización se refiere a textos centrados en el contar como instrumento para el conocimiento de la realidad (7) y la enmarcación, a obras que crean marcos estructurales dentro de los cuales se desarrollan otras (11). Otro estudio con este enfoque es el de Hahn (1977), quien destaca el final in absentia del texto: "el lector del cuento es capaz de completar unívocamente, fuera del texto, el desenlace que le ha sido escamoteado" (123). Hahn parte de los conceptos de narración enmarcada y mundo enmarcado, además de subrayar la importancia del lector cómplice, que en este caso "deviene co-autor intelectual del crimen" (128), mientras que el lector-personaje es un "suicida involuntario" (128). Ideas con las cuales no concuerdo.

Por su parte, Puleo (1990), también dentro de esta vertiente, se ha ocupado en anotar la "creencia en la unidad fundamental de la realidad" (25) como característica común entre Cortázar y los románticos alemanes, la cual posibilita "la confusión de planos de realidades distintas" (25) que se da en "Continuidad de los parques”, más particularmente, la confusión de los planos del "arte y los de la realidad" (59). Confusión que es apreciable desde el título mismo del cuento y que ha sido trabajada extensamente por Genette bajo el concepto de metalepsis: "intrusión del universo diegético en el universo extradiegético" (59).

Alazraki (1994) se limita a apuntar "el canje en el que el código realista cede a un código que ya no responde a nuestras categorías causales de tiempo y espacio" (69) y la búsqueda del "reverso de nuestra realidad fenomenal, un orden escandalosamente en conflicto con el orden construido por nuestro pensamiento lógico" (69). Block (1994) parte de los conceptos narrador y narratario de Genette para señalar su dependencia: "la vida del narrador depende del narratario como el cuento depende del narrador" (162). Block también hace referencia a la "textualización del lector" (162), a la metalepsis, a la "mecánica metaliteraria: la operación de leer puesta en escritura" (165) y a un parentesco entre el personaje-lector y el lector arquetípico de Balzac. Algunas de estos planteamientos resultan valiosos para la lectura que propongo, pero con lo que definitivamente no estoy de acuerdo es con la consideración de que "el lector muere a fin de dar testimonio de su 'willingsuspension of disbelief'. Es otro mártir que da prueba de su función, que es su fe literaria" (Block 1994: 163).

Silva (1997) destaca el énfasis de la crítica en la fusión de planos y pasa a plantear el texto como la "escenificación de la ceremonia de lectura" (123). Se refiere a la relación intertextual del texto cortazariano con "El amante de Lady Chatterley" de D. H. Lawrence, donde Constance (guardabosque) y Mellos (amante) planean la 
muerte de Sir Clifford, marido inválido, lector de literatura fantástica y de misterio. Y concluye que la lectura en "Continuidad de los parques" es "agente de transformación trágica de los actantes" (219).

Del mismo modo, Ovares y Rojas (1999) describen las novelas o los libros como umbrales, espacios de tránsito de una dimensión a otra, ejemplificándolo con "Continuidad de los parques", donde el libro fascina al lector, quien capta y es captado. Asimismo, las autoras señalan que el movimiento hacia el sur, es el que posibilita "el tránsito del protagonista y los fantasmas" (14) en términos freudianos. Mientras que Herrero (2000), por su parte, se ocupa del lugar del lector en el texto, de cómo la ambigüedad, lo silenciado y lo implicado hacen más "activa y participativa la cooperación del lector" y cómo el último párrafo ofrece "una información que desconcierta al lector y confiere un nuevo sentido a todo lo narrado anteriormente o lo orienta hacia una dirección determinada que nos obliga a reconsiderar lo anterior y observar ciertos detalles" (214).

Di Gerónimo (2000) ubica "Continuidad de los parques" en los relatos de la primera época de Cortázar y resalta al lector cómplice y los riesgos que implica. Posteriormente, Di Gerónimo (2005) dará un paso más allá de la inmanencia al ubicar el texto en el contexto de la Posmodernidad, en la cual hay un cambio de episteme que en literatura pone en crisis la mímesis e instaura la duda en cuanto a los límites de la realidad y la ficción. Insiste, además, en ver al autor y al lector como hacedores del texto y hace referencia a la metalepsis.

Pérez (2004) centra su atención en el doble narrativo como estrategia literaria, aspecto en el cual discuerdo, pues aunque dicha estrategia es visible en varios textos de Cortázar, no lo es en "Continuidad de los parques", donde lo que se da es un movimiento contrario: la fusión. Pérez parte de los conceptos de lector empírico, lector modelo de primer nivel y lector modelo de segundo nivel, así como los de trama, fábula y discurso propuestos por Eco.
Pellegrino (2006) afirma que en "Continuidad de los parques" se da un triunfo del "mundo imaginario y mental sobre el mundo real y cotidiano" (62) y que "el hombre sentado en el sillón que lee la novela escapó de su rutinaria vida a través de la muerte", mientras que el libro es el "medio informativo que anticipa el desgraciado final" (72). Lectura que nos parece muy alejada del texto, pues en lugar de separar tajantemente lo imaginario y lo real, los funde en un continuum.

Otra lectura inicialmente inmanente es la de Zavala (2007), quien se ocupa de señalar los espacios (300), la estructura (301), los narradores (302), la metalepsis (303), aspectos meramente estructurales, y pasa rápidamente a una lectura que no solamente se sale del texto, sino que carece de ligamen con él: elucubra toda una serie de posibles continuaciones para el texto, como si se tratara de un taller de escritura o reescritura. Un aspecto rescatable del estudio de Zavala es que pone de relieve la "alusión paródica al cuento policíaco" (305), ya que en "Continuidad de los parques" se subvierte dicha lógica, como destacaremos más adelante.

Así como Zavala, Meyer (2010) se centra en los procedimientos de la narración paradójica, tales como la metalepsis, la cual se emplea en la construcción de lo fantástico. La metalepsis es entendida por Meyer como la transgresión de los límites, la cual a su vez "pone en entredicho el funcionamiento del mundo de la ficción (240). Sopranzi (2010) anota aspectos como la recursividad, la circularidad y la relatividad del cuento. Destaca "la desaparición de una concepción temporal unívoca" (53) y el contraste realidad/ficción, ya que "ambas constituyen dos realidades igualmente verdaderas y equivalentes, puesto que la realidad es una narración" (54). El punto de partida de Sopranzi es inmanente en tanto parte de la literatura como lenguaje y el lenguaje como sistema cerrado. Por su parte, Наташа (2011) destaca también la metalepsis en los relatos de Cortázar y destaca "el propósito de cambiar la manera de ser lector y autor" (64).

Todos estos estudios centran su atención en lo fantástico desde la perspectiva de Todorov, posible razón de su abordaje inmanentista de 
"Continuidad de los parques", texto que exige una interpretación que trascienda su mera composición (sintaxis y semántica) y se tome en cuenta el carácter pragmático del proceso de lectura. Como pionero en la teorización entorno a lo fantástico, Todorov marcó una dirección y excluyó la interpretación alegórica-metafórica. Esta tendencia sobrevive en muchos lectores y críticos de nuestra literatura, quienes, además, desconocen otras posibilidades de concebir lo fantástico fuera de las pautas todorovianas.

Otro aspecto que merece ponerse de relieve en la crítica de "Continuidad de los parques" es la constante referencia a Borges. González (1973) lee el texto de Cortázar a partir de Borges, particularmente a partir de "El sur", propuesta que nos parece bastante pertinente tomando en cuenta las relaciones intertextuales entre ambos cuentos. Hahn (1977) señala el desenlace paralelo en ambos cuentos, ya que los toma como modelos del fin in absentia. Puleo (1990) retoma a Genette y su reflexión en torno a que "si un personaje puede ser lector o espectador, nosotros lectores o espectadores, podemos ser personajes de un relato que desconocemos" (59). Block (1994) señaló que en el texto cortazariano era visible la presencia de la "estética de Las ruinas circulares", en la que "la propia imagen se convierte en la imagen de otro que nos mira" (165). Silva (1997) evidencia una semejanza entre "Continuidad de los parques" y "El jardín de los senderos que se bifurcan", pues considera que en ambos casos "la operación de la lectura es escenificada ceremonialmente como una repetición circular" (124), parentesco retomado también por Di Gerónimo (2005). Pellegrino (2006) relaciona "Continuidad de los parques con "la multiplicidad eterna del personaje y su circunstancia", "la multiplicación infinita de miles de realidades exactamente iguales e irrevocables" (71).

Las apreciaciones que vinculan "Continuidad de los parques" con "El sur" nos parecen importantes, así como las reflexiones en que se nos advierte que podemos ser personajes de un relato; sin embargo, en cuanto a la circularidad y multiplicidad debemos ser cautelosos, ya que si bien el texto inicia y termina del mismo modo: un hombre en un sillón leyendo una novela, y hay un juego de cajas chinas: la novela leída por un lectorpersonaje que a su vez es leído por el lector externo, no juzgo adecuados los calificativos de una repetición infinita, eterna y circular, ya que dicho juego en "Continuidad de los parques" es diferente a la apertura infinita de Borges: es más probable la muerte del lector-personaje en Cortázar que el lector sumido en miles de espejos y laberintos de borgesianos.

Un último aspecto que nos interesa traer a colación es el hecho de que buena parte de la crítica en torno a "Continuidad de los parques" posee un enfoque biográfico, tal es el caso concreto de Sordo (1984) y Sosnowski (2000). Aunado a esto, abundan las lecturas en las que se lee a Cortázar desde Cortázar, que intentan corroborar los propósitos expresados por el autor en textos narrativos posteriores (Rayuela, 1963) o en textos ensayísticos (cf. García Ramos 1985: 51, Наташа2011: 64) en "Continuidad de los parques". Este tipo de lecturas se han transformado en todo lo contrario de lo que plantean los textos: la preocupación por el lector se ha visto empañada por la autoridad que la crítica le ha otorgado insistentemente al autor, aún cuando ya en 1968 Roland Barthes declaró la muerte del autor.

Además, la pretensión de hacer calzar los planteamientos del autor con sus textos, ha llevado incluso al error de ver la propuesta cortazariana del lector cómplice (1963) como coincidente con el surgimiento de la Estética de la recepción (finales de 1960) y de ahí repujársela a un texto de 1956 como "Continuidad de los parques".

El estudio de Juan Navarro, aunque de 1992, es de todo lo leído sobre "Continuidad de los parques" el que considero más acertado, ya que va más allá de la metalepsis y, como dice explícitamente, realiza una "lectura metafórica" (24) del cuento, el cual ve como "una alegoría del acto de leer" (241). La lectura de Navarro parte desde el mismo Cortázar con su propuesta del lector hembra y el lector alondra explicada en los capítulos 79 y 99 de Rayuela, así como de los planteamientos de Barthes en torno al 
placer y al gozo, ya que el lector-personaje del cuento es semejante al lector hembra y al lector alondra, y al lector que disfruta del placer, el lector pasivo y consumidor de $S / Z$. Juan apunta que "se trata de un lector ocasional burgués que utiliza la literatura como mera evasión, una distracción más en medio de su rutina diaria" (1992: 244), es decir, un lector pasivo y alienante, que Cortázar denominó lector hembra, un lector de novela de consumo, de personajes planos, discurso lineal, trama fácil, para quien el libro no es más que un objeto de culto o una pieza de colección que le brinda el placer elemental. Según Juan, el espacio desde donde el lector del relato lee se configura como símbolo de lo racional y lo estático, en oposición al bosque-naturaleza dinámica, en la que tiene lugar "la ceremonia de transgresión de los amantes" (1992: 247), la acción y la agresión. Concuerdo con Juan cuando apunta que "el asesinato del lector en la obra es, en última instancia, un asesinato epistemológico. Lo que muere en el texto es todo un concepto de lectura como asimilación de productos "premasticados"' (1992: 247). También me parece acertado aquello de que "al desasosiego borgeano que se desprende de la posibilidad de que nosotros, lectores, podamos ser leídos, se suma el peligro de nuestra aniquilación por el texto" (Juan 1992: 247).

\section{2. "Continuidad de los parques": una poética de lectura}

Es a partir de esta primera piedra puesta por Juan que surge mi lectura de "Continuidad de los parques" como un poética de la lectura, como un deber ser del proceso de leer. Desde la Poética de Aristóteles se entiende por el término "una disciplina cuyo objeto es la elaboración de un sistema de principios, conceptos generales, modelos y metalenjuage científico para describir, clasificar y analizar las obras de arte verbal o creaciones literarias" (Estébanez 2001: 858). En el caso de "Continuidad de los parques", dicha formulación del sistema de conceptos, principios, modelos y terminología científica para el estudio de los fenómenos literarios, no se aboca a la construcción del texto literario, tradición ampliamente difundida en la literatura; sino, por el contrario, al proceso de lectura. Esto dado que el personaje principal es el lector de una novela que terminará por matarlo debido a su manera superficial y ligera de leer. Esa experiencia de lectura del personaje se nos muestra a los lectores de modo ejemplarizante, marca un cómo no se debe leer y por lo tanto sienta las bases de un modelo y un antimodelo de lector.

\subsection{La apertura de lo fantástico}

Como bien ha señalado unánimemente la crítica "Continuidad de los parques" es un cuento fantástico. Sin embargo, a la luz de nuevas teorías como la de Roas, considero que su carácter fantástico no reside únicamente en la tan citada metalepsis, sino que es mucho más abarcador. Para Roas, lo fantástico está entrañablemente ligado a la transgresión, a la abolición de las fronteras, de ahí que se susciten las transposiciones de planos o niveles narrativos, de espacio y de tiempo. En "Continuidad de los parques" dicha transgresión es extensiva a esas tres áreas y no solo a los planos narrativos. Realidad y ficción se funden en un continuum, alterando el tiempo y el espacio. El cuento inicia en presente, nos transporta a un futuro (plan de asesinato) y un pasado (ejecución de dicho plan) para finalizar de nuevo en el presente de quien lee. Esta mezcla y fusión de temporalidades no hace otra cosa que mostrarnos, como señala Roas, el carácter maleable del tiempo y del espacio. El cual, al hacerse palpable, destruye todas las certezas, todo se vuelve incertidumbre, lo que creemos hasta entonces "realidad" pasa a ser una "construcción subjetiva" (Roas 2011: 26), y en tanto construcción, análoga a la literatura: "la realidad es vista como compuesto de constructos tan ficcionales como la propia literatura" (Roas 2011: 29). Realidad y literatura son homólogas, ambas están hechas del mismo y arbitrario material: el lenguaje. No son antitéticas como concibe el lector-personaje, sino que forman un todo, por ello es posible que lo que se encontraba 
"dentro" del texto, termine "fuera" del texto; y lo que estaba "fuera" del estudio acabe "dentro" de él. Contrario a lo que considera el lectorpersonaje, no existen adentros y afueras, solo continuidad. Los parques no se desdoblan, sino que se funden, por eso la mejor imagen para este concepto de realidad-literatura es la banda de Moebius, "símbolo de los opuestos que coexisten" (Hadatty 2009: 4), que forman parte de un todo "continuo e ilimitado" (Наташа2011: 65).

Precisamente, debido a esa continuidad que el texto resalta, no es favorable quedarse únicamente en la inmanencia de este texto. $\mathrm{La}$ irrupción de lo imposible: que los personajes de la novela que leo me ataquen, no se queda únicamente en el texto, sino que tiene efectos pragmáticos en el lector externo del cuento. Efectos que lo fantástico potencia al construir una "realidad intratextual semejante a la suya" (Roas 2011: 32) e irrumpir con lo imposible. Lo fantástico se "proyecta a la extratextualidad" (Roas 2011: 32), produciendo una desestabilización del lector y su proceder epistemológico. Y provocándole, además, lo que Roas denomina miedo metafísico, es decir, "la impresión inquietante sobre el receptor" (Roas 2011: 103). Como señala Ortega, debido a su carácter transgresor y subversivo, lo fantástico se torna relativista y por tanto critica "el orden mental e ideológico del individuo" (Ortega 1986: 134).

Para Cortázar, literatura y realidad forman parte de un mismo continuum, la realidad es una sola, es "la nuestra, pero con los límites estirados" (Ledesma 2009: 2). La realidad de Cortázar abarca todo, lo superficial y lo profundo, el "piso de arriba" y el "piso de abajo" (Cortázar 1989: 12), lo que vemos y lo que aún no alcanzamos a ver. De manera que la literatura también sería un todo abarcador, pues finalmente, ateniéndonos a esa idea de realidad, "toda literatura es fantástica" (García 1976: 78) y por lo tanto la poética de lectura expuesta en "Continuidad de los parques" no es exclusiva de la literatura fantástica, sino que se abre a la literatura en general, transgrediendo no solo los límites de su género (cf. Sordo 1984: 27), sino también los de su propia estética.

\subsection{El lector antimodelo y el lector modelo}

\subsubsection{El lector antimodelo}

El título "Continuidad de los parques" constituye la primera pista que el narrador del cuento brinda al lector externo para que, a diferencia del lector-personaje, advierta la continuidad que existe entre la realidad y la ficción y no le sobrevenga la muerte. El título del cuento pone de relieve que lo que el lectorpersonaje toma como dos parques independientes uno del otro, son en realidad una continuidad que él no supo ver, ya que su tránsito de uno a otro (real a ficcional) fue sin darse cuenta. Sin embargo, tal experiencia se narra a la espera de que el lector externo sea consciente de la continuidad.

Desde la primera línea del cuento, se nos presenta a un lector-personaje cuyo final trágico se debe a la novela que lee, pues ignora que forma parte de ella y que por tanto su muerte ya estaba programada: "todo estaba decidido desde siempre" (Cortázar 1972: 10). Al interpretar el cuento como una poética del proceso de lectura, la historia del lector muerto por la novela adquiere un carácter ejemplarizante y aleccionador para el lector externo: mientras que la novela leída por el lector-personaje mata, el cuento leído por el lector externo alecciona. Es importante retomar en este punto algunas consideraciones con respecto a la novela y el cuento. Según Edgar Allan Poe, de quien Cortázar es traductor y fiel lector, la novela tiene la desventaja de ser objetable, ya que esta

como no puede ser leída de una sola vez, se ve
privada de la inmensa fuerza que se deriva de la
totalidad. Los sucesos del mundo exterior que
intervienen en las pausas de la lectura modifican,
anulan o contrarrestan, en mayor o en menor grado,
las impresiones del libro (1976: 13).

Mientras que el cuento resulta, para Poe, un mejor aliado: "El cuento breve, en cambio, permite al autor desarrollar plenamente su propósito... Durante la hora de lectura, el alma del lector está sometida a la voluntad de aquel" (1976: 13. El destacado es mío). 
Con respecto a esta última frase Cortázar comenta en su prólogo a los cuentos de Poe: "Esta última frase es reveladora. Poe escribirá sus cuentos para dominar, para someter al lector en el plano imaginativo y espiritual" (1976: 13. El destacado es mío). En relación con "Continuidad de los parques", vemos que el lector-personaje actúa según estas líneas descritas por Poe, se somete a la novela que lee y evita, dando la espalda a la puerta, la "irritante posibilidad de interrupciones" (Cortázar 1972: 9). Por otra parte, si tenemos en cuenta lo señalado por Juan acerca de que este lector-personaje es un lector de placer en términos de Barthes, hay que destacar que para Barthes la novela como tal está ligada a la lectura de placer que persigue únicamente la satisfacción de "conocer el fin de la historia" (1978: 18), el "develamiento del enigma" (1978: 19). Vemos entonces cómo el lector-personaje es configurado en el cuento como un antimodelo de lector, pues lee para satisfacer su vano y efímero placer.

El lector-personaje es un lector enajenado que carece de capacidades cognitivas y epistémicas que le permitan hallar en el texto leído las claves o señales que le posibiliten la lectura de su propio mundo, de su realidad. Nos encontramos ante un lector que no posee la capacidad de vincular realidad y literatura, y por lo tanto no sabe leer provechosamente ni la realidad ni la literatura. En su mundo real, desconoce que su mujer lo engaña y ha urdido un plan en conjunto con su amante para asesinarlo. En el mundo novelesco es incapaz de leerse en la novela, de reconocerse como personaje. Este es un lector vencido por la novela que lo gana, lo desgaja y lo absorbe(Cortázar 1972: 9). La novela lo anula por completo, dado que él ha decido leer de espaldas a la puerta, simbólicamente se trata de leer de espaldas a la realidad, cerrar ese umbral o pasaje. Este lector se deja envolver fácilmente por la trama y no toma en cuenta que lo leído puede tener consecuencias en él y en su realidad. Es significativo que paralelo a la puerta, como umbral que comunica con la realidad a la cual se le da la espalda, el libro-novela y los ventanales fungen también como umbrales de la ficción y que devoran al lector. La ventana de la casa como análoga al ojo humano, sirve para ver. La función de la ventana radica en permitir la entrada de "aire y luz" (Chevalier1986: 1055); sin embargo, la luz, símbolo de conocimiento y saber, nunca se menciona en el estudio, sino hasta la última línea: "La puerta del salón, y entonces el puñal en la mano, la luz de los ventanales, la cabeza del hombre en el sillón leyendo una novela" (Cortázar 1972: 11. El destacado es mío), cuando ya el asesino ha irrumpido en el estudio y le llega al lectorpersonaje por la espalda. Estos ojos-ventanas no iluminan, así como los ojos del lector no leen más allá de lo que está escrito. Él es un lector de superficies y por tanto en desventaja frente a sus asesinos, quienes, con los pies en el suelo, conocen perfectamente su realidad y la tienen medida y calculada. Mientras que el lectorpersonaje disfruta del aire que danza bajo los robles, su mujer y el amante de esta, andan por el mundo de "hojas secas" y "senderos furtivos" (Cortázar 1972: 10). El primero en la superficie, los segundos en lo profundo.

Pero, más allá de las actitudes y aptitudes con que este lector se dispone a leer, hablemos ahora de qué es lo que lee. Sabemos con certeza que se trata de una novela, que según algunos críticos sería del subgénero policíaco. Como ya advertí anteriormente, concuerdo con Zavala al señalar que "Continuidad de los parques" presenta una parodia de la novela policíaca, ya que si en la policíaca el esquema fundamental consiste en "presencia de un crimen, investigación del mismo por un detective, descubrimiento y persecución de los culpables" (Estébanez 2001: 760), aquí encontramos la subversión de dicho orden. El crimen, que intuimos ocurre, se encuentra al final de la novela: "se puso a leer los últimos capítulos" (Cortázar 1972: 9). Además, es revelador que se aluda a la novela policíaca, considerada literatura popular, liviana o "paraliteratura" (Estébanez 2001: 760), ya que supuestamente no ofrece mayor reto intelectual al lector. En este punto creo pertinente ligar la novela que se lee en el cuento, no solamente con el subgénero policial, sino también con el rosa. La novela rosa también ha sido incluida dentro de la "paraliteratura o subliteratura" (Estébanez 2001: 764), dirigida a 
un público, predominantemente femenino y de escasa cultura, que busca en ella su evasión ensoñadora y una gratificación de sus deseos de felicidad, imaginada en el matrimonio ideal. El argumento, de gran simplicidad, se basa en el encuentro de una muchacha y un joven que van a topar con ciertas dificultades de formación de pareja motivadas por la diferente extracción social. Finalmente, el amor acabará superando estos impedimentos. Es un tipo de relatos caracterizados por una ausencia de sentimientos profundos, suplantados por un fácil erotismo, condicionado, a su vez, por una aparente y falsa moralidad (Estébanez 2001: 764).

Como se desprende de esta breve definición, la novela que lee el lector-personaje podría ser también una novela rosa, ya que consiste en un crimen pasional. Si nos atenemos al ligamen que se plantea con la novela rosa y la policíaca, es evidente que el cuento se refiere a un lector consumidor de bestseller, que no solo devora libros, sino que se deja devorar por los libros. Asimismo, resulta relevante el hecho de que se aluda a la novela rosa, ya que esta se vincula con las pasiones, con los sentimientos, con lo que se podría considerar lo más íntimo de la persona y aún así, el lector no alcanza a interpretar aquello que es lo más íntimo, ni en su realidad ni en la novela.

El carácter antimodélico del lector se hace visible, tanto en su manera de realizar el proceso de lectura, como en lo que lee. Sin embargo, como señala Barthes, un lector de gozo es capaz de realizar la lectura de placer y la de gozo, por lo tanto la responsabilidad no recae sobre lo que se lee sino sobre el lector, pues aunque lea paraliteratura podría no dejarse absorber por ella, podría revelarse contra la autoridad del autor, que como Poe, busca su sumisión.

\subsubsection{El lector modelo y otros lectores}

Una vez vistas las características del lector-personaje de "Continuidad de los parques", pasemos a ver las características del lector modelo que el cuento demanda. Como ya he dicho, la experiencia de lectura del lectorpersonaje se convierte en una lección para el lector externo, a quien se le propone no leer de espaldas al mundo, no dejarse envolver por la trama sin tomar en cuenta las consecuencias de lo leído, no ser un lector ingenuo, que se maravilla con la ficción sin tomar en cuenta la realidad. El lector modelo no es el que se deja ganar, desgajar y absorber por el texto, sino aquel que se aplica, en términos de Barthes, a: "no devorar, no tragar sino masticar, desmenuzar minuciosamente" (1978: 21).

"Continuidad de los parques", al presentar a un personaje que lee, nos conecta a su vez con otros lectores textualizados, tales como el don Quijote de Cervantes, el RoderickUsher de Poe y el Juan Dahlmann de Borges. Al tiempo que, al presentarnos a un personaje de ficción que desconoce su carácter ficcional, nos remite al Víctor Goti de Unamuno. En don Quijote los libros son una puerta de acceso a la realidad, son los que dirigen el actuar del personaje en tres niveles: a) estético: la literatura le sirve a don Quijote para escribir, b) ético: don Quijote asume los valores caballerescos expuestos en los libros a favor de los desposeídos y c) político: don Quijote actúa contra las injusticias y a favor de la libertad. Mientras que para el lectorpersonaje el libro es más un agujero negro que se lo traga y lo desconecta de la realidad, la cual no se ve afectada nunca por sus lecturas, pues: "Había empezado a leer la novela unos días antes. La abandonó por negocios urgentes, volvió a abrirla cuando regresaba en tren a la finca" (Cortázar 1972: 9). La lectura de la novela no tiene ningún efecto en él, lee y atiende sus negocios sin mezclar nunca las cosas. De ahí que contrario al lector-personaje del cuento, se demande un lector externo más similar a don Quijote, quien, además, es consciente de su realidad de personaje de ficción.

Con respecto a "La caída de la casa Usher", "Continuidad de los parques" presenta varios puntos en común: a) Conflicto pasional-sexual: Usher y su hermana mantienen una relación incestuosa, mientras que en el relato de Cortázar hay un triángulo amoroso entre la mujer, el lector-personaje y el amante de la mujer. b) $L a$ banalidad del libro leído: el amigo de Roderick confiesa que lee ese libro porque es el que tiene a mano pues en realidad "poco había en su 
prolijidad tosca, sin imaginación, que pudiera interesar a la elevada e ideal espiritualidad de mi amigo" (Poe 1976: 121), lo cual coincide con lo que ya he señalado respecto a la novela que se lee en "Continuidad de los parques". c) El sillón y la puerta: en el caso de Roderick, no lector sino oyente de lo leído, el texto señala que poco a poco su sillón se movió hasta quedar de frente a la puerta, desde la cual llegaría su hermana muerta a llevárselo. Por el contrario, como he señalado, en "Continuidad de los parques" la lectura se realiza de espaldas a la puerta. En el texto de Poe también es simbólico el hecho de estar de frente a la puerta, ya que Roderick sí es capaz de establecer una relación entre lo que le leen y su vida, su realidad inmediata. Usher sí se reconoce en lo leído y su muerte es liberadora, pues la lectura que emprende su amigo con fines terapéuticos, tiene resultados: por fin logra revelar su secreto y despojarse de lo que le atormentaba: haber enterrado viva a su hermana, liberación que podría verse como un efecto catártico de la lectura. En cuanto a la muerte del lector-personaje de Cortázar, habría que rescatar el hecho de que la muerte le llega como sanción a su modo pasivo de leer; al tiempo que, para nosotros, lectores externos, la muerte del lector-personaje se torna vicaria: gracias a ella podemos advertir los peligros de una lectura de espaldas a la realidad y salvarnos.

En relación con "El sur" (1953) de Jorge Luis Borges, Juan Dahlmann el lector y personaje se caracteriza por tratar de tapar la realidad con el libro: "decidió que nada había ocurrido y abrió el volumen de Las Mil y Una Noches, como para tapar la realidad" (1972: 203). Aquí el libro no es un umbral, sino un obstáculo, una barrera frente a la realidad y una barrera que le impide a Dahlmann ver las consecuencias reales que esto tiene y lo lleva más bien a justificar su muerte:

Dahlmann se inclinó a recoger la daga y sintió dos cosas. La primera, que ese acto casi instintivo lo comprometía a pelear. La segunda, que el arma, en su mano torpe, no serviría para defenderlo, sino para justificar que lo mataran. Alguna vez había jugado con un puñal, como todos los hombres, pero su esgrima no pasaba de una noción de que los golpes deben ir hacia arriba y con el filo para adentro (Borges 1972: 204).
Sin embargo, en el cuento de Borges esta muerte no es más que la muerte que Dahlmann "hubiera podido elegir o soñar" (Borges 1972: 204). Mientras que en "Continuidad de los parques", encontramos una parodia de Dahlmann como lector, cuya muerte está programada por el autor de la novela que lee. De ahí que el lector modelo no sea un cómplice del autor, sino un ente liberado de esa autoridad. En relación con esa autoridad del autor, es pertinente retomar a don Quijote y a Víctor Goti, ya que ambos personajes son conscientes de su realidad ficcional, contrario al lector-personaje de Cortázar, quien no se ve integrado como personaje en el texto que lee y por tanto ignora los mecanismos tejidos por el autor para causar su muerte.

"Continuidad de los parques" exige un lector externo que no se deje absorber por el texto, que no pierda sus facultades intuitivas, deductivas y cognitivas, sino que esté avisado, sea precavido y esté atento a las pistas que apuntan a una muerte. Si el lector del relato actúa como este se lo demanda y toma la distancia epistemológica requerida para realizar una lectura de gozo, entonces, al intuir la muerte del lector-personaje no está siendo cómplice del crimen, como otros han dicho, sino testigo de una muerte que no puede evitar; pero, que le permite evitar la suya propia. Si bien la muerte del lector-personaje no queda explícita en el relato, dado que el lector modelo no necesita que el autor le dé todo listo y masticado y es capaz de utilizar sus capacidades cognitivas, puede completar el desenlace del relato y atestiguar la muerte con todas las implicaciones que ello tiene. Se atestigua, se declara para lograr la condena del asesino, delatarlo y a la vez liberarse uno mismo de la culpa. La culpa de una lectura puramente placentera está en el texto diseñado para tal efecto, y por tanto en el autor autoritario que lo diseña, así como en el lector alienado que ignora que al leer de esa manera ejecuta su propia muerte y nunca se entera de su estatuto ficcional. Este lector-personaje devora para ser 
devorado: el placer lo conduce al padecer, sin que se percate.

\section{Conclusiones}

"Continuidad de los parques" es un cuento ampliamente estudiado y que sin embargo, no agota aún las posibilidades de lectura. A pesar de ello, considero fundamental dar un giro teórico en cuanto a los acercamientos que a él puedan hacerse, ya que al plantear una continuidad entre literatura y realidad, el texto mismo exige una interpretación que trascienda la inmanencia que hasta ahora ha primado en la crítica.

Como poética del proceso de lectura "Continuidad de los parques" nos invita a los lectores a independizarnos del autor, a no ser cómplices de nuestro propio asesinato, a leer sin dejarnos arrastrar por el texto, a dominar el texto y no que él tome el control. A través del recurso intertextual, "Continuidad de los parques" señala las pautas que debe seguir un lector modélico: debe ser similar a don Quijote, quien con los libros destapa la realidad, quien no se queda en la biblioteca, sino que sale de ella transformado y a transformar su realidad. El lector modelo debe ser también semejante a Roderick, en cuanto a que él es capaz de relacionar la lectura con lo vivido. Pero, el lector modelo debe distanciarse de Dahlmann quien busca esconderse de la realidad en el libro. El lector modelo no es lector cómplice del autor y que le permite ganar el juego, no es cómplice de un autor bestseller que solamente busca consumidores. El lector, externo, de "Continuidad de los parques" no puede ser un lector cómplice a menos que anhele ensuciarse las manos con la sangre del lector-personaje y esté buscando morir de la misma manera. Ante la angustia que como lectores externos podemos experimentar al pensarnos como personajes de un texto que desconocemos, "Continuidad de los parques", nos ofrece la opción de distanciarnos del procedimiento seguido por el lector-personaje y no ser asesinados por el texto.

\section{Nota}

1. Suspensión voluntaria de la incredulidad.

\section{Referencias bibliográficas}

Alazraki, Jaime. 1994. Hacia Cortázar: aproximaciones a su obra. Barcelona: Anthropos.

Barthes, Roland. 1978. El placer del texto. México D. F.: Siglo XXI Editores.

Block, Lisa. 1994. Un lector leído. En: Block, Lisa. Una retórica del silencio. Funciones del lector y los procedimientos de la lectura literaria. México D. F.: Siglo XXI Editores: 161-174.

Borges, Jorge Luis. 1972. Ficciones. Madrid: Alianza Editorial.

Chevalier, Jean. Dir. 1986. Diccionario de los símbolos. Barcelona: Editorial Herder.

Cortázar, Julio. 1989. Historias de cronopios $y$ famas. Buenos Aires: Editorial Sudamericana.

Cortázar, Julio. 1976. Los relatos, 2 Juegos. Madrid: Alianza Editorial.

Cortázar, Julio. 1972. Final del juego. Buenos Aires: Editorial Sudamericana.

Di Gerónimo, Miriam. 2005-2006. Laberintos verbales de autoficción y metaficción en Borges y Cortázar. Cuadernos del CILHA, 7-8: 91-105.

Di Gerónimo, Miriam. 2000. Poética del cuento de Julio Cortázar. Revista de Literaturas Modernas, 30: 67-86. 
Estébanez Calderón, Demetrio. 2001. Diccionario de términos literarios. Madrid: Alianza Editorial.

García Ramos, Arturo. 1985. El principio y el fin de los cuentos de Julio Cortázar. Anales de literatura hispanoamericana 14: 47-55.

García, Eladio. 1976. Lo fantástico y el problema de su interpretación en los relatos de Julio Cortázar. Revista Chilena de Literatura, 7: 77-106.

González, Eduardo. 1973. Hacia Cortázar, a partir de Borges. Revista Iberoamericana, 84-85: 505-520.

Hadatty Mora, Yanna. 2009. Julio Cortázar, la prosa de Moebius. Revista Digital Universitaria, 5: 1-8.

Hahn, Óscar. 1977. El motivo de los mundos comunicantes. Sobre 'Continuidad de los parques’ de Julio Cortázar”. Texto Crítico 7: 123-128.

Наташа Б. Филиповић. 2011. Discurso metapoético en los cuentos de Julio Cortázar. Речu, 4: 63-75.

Herrero Cecilia, Juan. 2000. Estética y pragmática del relato fantástico. Castilla: Universidad de Castilla-La Mancha.

Juan Navarro, Santiago. 1992. 79 o 99 /modelos para desarmar: claves para una lectura morelliana de 'Continuidad de los parques' de Julio Cortázar. Hispanic Journal, 2: 241-249.

Lagmanovich, David. 1972. Rasgos distintivos de algunos cuentos de Julio Cortázar. Hispamérica, 1: 5-15.
Ledesma, Agustina. 2009. La otra orilla de lo fantástico en Julio Cortázar. Actas del II Congreso Internacional 'Cuestiones críticas': 1-9.

Meyer Minnemann, Klaus. 2010. Narración paradójica y construcción de lo fantástico en los cuentos de Julio Cortázar. Nueva Revista de Filología Hispánica, 1: 215-240.

Ortega, José. 1986. La dinámica de lo fantástico en 4 cuentos de Cortázar. Revista de Crítica Literaria Latinoamericana, 23: 127-134.

Ovares, Flora y Rojas, Margarita. 1999. Espacios de tránsito en los cuentos fantásticos de Julio Cortázar. Letras, 31: 5-23.

Paredes, Alberto. 1988. Abismos de papel. Los cuentos de Julio Cortázar. México D. F.: UNAM-Universidad de Guadalajara.

Pellegrino, Ayelen. 2006. La victoria del mundo imaginario sobre el mundo cotidiano en los relatos de Julio Cortázar. Universidad Nacional de Quilmes, 4: 62-78.

Pérez Cervantes, Abel. 2004. Las estrategias narrativas del doble literario en 'Continuidad de los parques' de Julio Cortázar. Escritos, 30: 177-188.

Poe, Edgar Allan. 1976. El escarabajo de oro y otros cuentos. Trad. y prólogo de Julio Cortázar. San José: EDUCA-ECR.

Puleo, Alicia. 1990. Cómo leer a Julio Cortázar. Madrid: Ediciones Júcar.

Roas, David. 2011. Tras los límites de lo real. Una definición de lo fantástico. Madrid: Editorial Páginas de Espuma. 
Silva Cáceres, Raúl. 1997. El árbol de las figuras. Estudio de motivos fantásticos en la obra de Julio Cortázar. Santiago: LOM Ediciones.

Sopranzi, Michela. 2010. Julio Cortázar: un escritor sistémico. Tesis. UniversitätWien.

Sordo, Enrique. 1984. Cortázar o la transgresión de los límites. El Ciervo, 396: 27.
Sosnowski, Saúl. 2000. Cortázar, necesario. Orbistertius, 7: 1-7.

Zavala, Lauro. 2007. Continuaciones para 'Continuidad de los parques' de Julio Cortázar. En: Zavala, Lauro. Ironías de la ficción y la metaficción en cine $y$ literatura. México D. F.: UACM: 299-311. 